\title{
From the President
}

\section{ALCTS Annual Report, 2019-2020}

\author{
Jennifer Bowen, ALCTS Past-President
}

A fter serving as ALCTS President from July 2019 to June 2020, I have the A privilege of presenting the final Annual Report for ALCTS as the division concludes its existence on September 1, 2020. The end of ALCTS's more than sixty-year history under the name the Association for Library Collections \& Technical Services, and before that the Resources and Technical Services Division, is yet the latest milestone in ensuring that ALA provides an appropriate and sustainable organizational structure to support the work of library professionals and others who work with library collections. We now can celebrate the launch of the new ALA division, Core: Leadership, Infrastructure, Futures, as a member-driven venture created collaboratively by members of ALCTS, the Library Information Technology Association (LITA), and the Library Leadership \& Management Association (LLAMA).

In my editorial in the July issue of LRTS, I wrote that we have a lot to celebrate in both the promise of our new division and in the many accomplishments of ALCTS and ALCTS members. In this report, I will highlight some of these accomplishments. Prior to becoming part of Core, ALCTS consisted of roughly a hundred member-driven committees, interest groups, and other working groups that mostly continued their activities from 2019 through 2020 within the context of a possible transition to Core. This report celebrates the continued work of ALCTS members despite the uncertainty about the future of the division.

I am indebted to Kerry Ward and all of the former ALCTS (and now Core) staff at ALA for their efforts to collect and organize this information. My thanks also to the ALCTS Planning Committee, chaired by Katharine Leigh, for organizing the achievements of many ALCTS groups and mapping them to the ALCTS 2019 Strategic Plan.

\section{ALCTS 2019 Strategic Achievements}

With the knowledge that the ALCTS, LITA, and LLAMA Boards and memberships might be voting in early 2020 to create a new division, the ALCTS Board approved a one-year Strategic Plan in June 2019 to guide ALCTS activities from 2019 to 2020 , during what indeed ended up to be a transitional year. This oneyear plan focused on two priority areas that the Board assessed would serve ALCTS well whether or not the votes to create Core took place later in the year. Primary among these priorities was to infuse each of the division's goals with strengthening ALCTS's focus upon diversity, equity, and inclusion, thus more fully aligning ALCTS with the mission, vision, and values being proposed for the

Jennifer Bowen (jbowen@library.roch ester.edu) is Associate Dean, Scholarly Resources and Curation, University of Rochester River Campus Libraries. She is the outgoing President of ALCTS, the Association for Library Resources and Technical Services (2019-2020). new division and with ALA's Core Values of Librarianship. Second, the strategic plan prioritized ALCTS activities to examine its own organizational structure with an eye toward sustainability whether ALCTS became part of a new division or not. During this transitional year, ALCTS achieved the following milestones toward accomplishing the goals in this plan: 


\section{Goal I. Strengthen advocacy for equitable access to and preservation of resources and information for all users.}

ALCTS's efforts in this area spanned publications, programming, and advocacy. A few highlights follow:

- The eScholarly Communication Interest Group sponsored programming at Midwinter 2020 to support the resource acquisition and lifecycle of open access monograph publishing;

- The ALCTS journal, LRTS, continues to provide author-friendly copyright terms for published articles; and

- The ALCTS Monographs group published many resources on equitable access and preservation, such as the 2019 publication Assessment Strategies in Technical Services, which broadly addresses equitable access for users.

\section{Goal II. Assess current divisional programs and services}

ALCTS committees and interest groups worked with LITA and LLAMA to advance a new division and identified opportunities to streamline the work of the division and its sections to prepare for future organizational changes. The ALCTS Interim Executive Director served on the ALA Steering Committee for Organization Effectiveness (SCOE) and advised the ALCTS Board on how ALCTS might be affected by that group's work. Additional activities related to this goal included:

- In collaboration with the LLAMA Mentoring Committee, the ALCTS Leadership Development Committee opened participation in this year's mentoring program to current members of ALCTS, LLAMA, and LITA;

- The Advocacy and Policy Committee recommended a group within Core to advocate specifically for technical services staff within ALA and libraries; and

- The ALCTS Standards Committee worked closely with the CRS Standards Committee to develop a new draft charge for a potential merged committee under Core.

\section{Goal III. Strengthen our diversity and inclusiveness}

From 2019 to 2020, ALCTS groups focused upon the plan's subgoal to "Reach out to historically under-represented groups to increase awareness and encourage their participation." Selected highlights are:
- The Technical Services Directors of Large Research Libraries Interest Group held a session at Midwinter 2020 on prioritizing diversity in collections backlogs;

- The ALCTS/LITA/LLAMA Presidents Program Committee planned the three divisions' first joint Presidents' Program for Annual 2020 to feature Dr. Meredith Clark, assistant professor in the Department of Media Studies at the University of Virginia (UVA) and media consultant for diversity, ethnicity, and inclusion in a program that would explore how libraries can respond to traumatic/sudden events in their communities, both short- and long-term. With the cancellation of the in-person ALA Annual Conference, Dr. Clark has been rescheduled as a keynote speaker for the Fall 2020 Core Forum;

- In late summer 2019, the ALCTS Board collaborated with other ALA divisions to sponsor thirty-five ALCTS leaders to participate in Hollaback!'s online Bystander Training. The goal of this training was to empower those who attended to respond when an incident of deliberate or unconscious bias occurred during an ALCTS event or meeting; and

- Several ALCTS Division Committees, such as the Continuing Education Committee, the Monographs Series Editorial Board, the Program Committee, and Publications Committee actively cultivated and promoted inclusion of under-represented groups in their work, including open calls for participation in webinar development and publications, highlighting proposals from persons of underrepresented groups and incorporating diversity and inclusiveness in the evaluation of program proposals.

\section{Goal IV. Develop and promote Association activities in multiple formats to increase opportunities for virtual and year-round participation}

ALCTS groups made significant progress toward this goal, even before COVID-19 necessitated the cancellation of the in-person 2020 ALA Annual Conference. While ALCTS continued to have a presence at ALA Midwinter 2020 in Philadelphia, many ALCTS committees and interest groups opted to hold their Midwinter meetings online to increase committee participation among members who could not attend the conference in person. In addition:

- The Continuing Education Committee continued its work of providing numerous webinars throughout the year, including offering free e-Forums;

- The ALCTS Publications Committee offered presenters at conferences an avenue to publish with 
ALCTS, thereby broadening the reach of their presentation from the conference to the greater community;

- The ALCTS Fundraising Committee raised funds for in-person and virtual events, such as Preservation Week, Preservation in Action, ALA Annual preconferences, the President's Program, the Midwinter reception, ALCTS/LITA/LLAMA Exchange, webinars, and the Fundamentals courses; and

- In May 2020, the three divisions worked together to deliver a virtual conference, The Exchange: An ALCTS/LITA/LLAMA Collaboration" (details below).

\section{ALCTS Activities by Area, 2019-2020}

With much of the attention of ALCTS members during the 2019-2020 timeframe focused on envisioning a possible future for the division's work as a part of Core, some ALCTS committees were less active during this time than in previous years. Nevertheless, many essential ALCTS and ALCTS section groups continued their work without interruption and provided continuing value to ALCTS members in areas including continuing education, professional development, leadership development, standards development, and advocacy. Because many of these activities were ongoing from previous years or were planned before the revised 2019 Strategic Plan was approved, they were more closely aligned to the overall mission of ALCTS rather than the specific goals in the plan.

Programming and Continuing Education continued to be a strength for the division. For many years ALCTS provided programming in multiple formats (physical and virtual), which was fortuitous this year with the reduction of a physical presence at the ALA Midwinter Meeting and much of the world working from home due to COVID-19. With the cancellation of many in-person events, ALCTS groups and members quickly and successfully transitioned their activities to a virtual environment.

\section{ALCTS Awards}

ALCTS award juries selected deserving award recipients for twelve division and section-level awards; in addition, three ALCTS members were selected by the ALCTS President to receive Presidential Citations for their contributions to planning for Core. Zoë McLaughlin, South and Southeast Asian Studies Librarian at the Michigan State University Libraries, was selected as the ALCTS-sponsored Emerging Leader for 2019-2020. Nearly one hundred ALCTS members, award recipients and their family, friends and colleagues attended the virtual ALCTS Awards Ceremony on July 14, 2020, which was followed by a virtual ALCTS Happy Hour with about fifty attendees.

\section{ALCTS Continuing Education}

Seven Fundamentals courses were offered this year, covering Acquisitions, Electronic Resources, Collection Development and Management, Collection Assessment, Preservation, Cataloging, and Metadata. More than five hundred and fifty individuals registered for the courses. ALCTS also offered over twenty webinars in FY21, including two that were presented for free during Preservation Week. Overall, nearly seven hundred individuals and groups registered for webinars.

\section{Conference Programming}

Prior to the move from an in-person to a virtual ALA Annual, the ALCTS Program Committee developed a full slate of programming with an increasing focus on topics advocating equitable access to resources. This included a preconference on cataloging ethics and preservation in times of crisis, among others. ALA selected two ALCTS programs for Virtual Annual: "Happy Together?: Communication and Collaboration Between Technical Services and IT" and "The Technical Services Learning Organization: Transformation through Training and Development." The individuals who had planned other programs have been offered the option to convert them to webinars, which should provide many possible programming topics for Core's inaugural year. The committee has incorporated diversity and inclusiveness as criteria in the evaluation of program proposals submitted. Prior to the cancellation of ALA Annual, program planners also explored with ALCTS staff how to promote inclusiveness during presentations through increasing the availability of microphones for audience questions and for speakers on panels so that all audience members could hear all aspects of the session. In lieu of face-to-face meetings at the Annual Conference, ALCTS also held a Virtual Interest Group Week during the week of June 8, 2020, with all events free of charge.

\section{ALCTS/LITA/LLAMA Exchange}

In May 2020, the three divisions worked together to deliver the Exchange: An ALCTS/LITA/LLAMA Collaboration. Using the successful 2017 ALCTS Exchange as a model, members from the three divisions collaborated for the better part of a year to develop an online conference with 
content and themes relevant across the three divisions. The ALCTS Office took the lead in managing the budget, contracting with external vendors, and providing staff support. ALCTS Past-President Kristin Martin chaired the Exchange Working Group. There were a total of 249 registrants, both groups and individuals. Hosting the Exchange across the three divisions provided an opportunity for the three divisions to work together and a launching point for the professional development activities of Core. The success of the event bodes well for it to become a staple of professional development for Core. Assuming a post-pandemic world supports in-person professional events, the Exchange Working Group recommended offering the Exchange in alternating years with the in-person Core Forum (which will also be held virtually in November 2020).

\section{Preservation Week}

This year marked the tenth anniversary of Preservation Week®, a public awareness initiative that aims to promote preservation and conservation in communities with the help of libraries, institutions, and museums. This year's theme was "Preserving Oral History," and author, activist and cultural critic Roxane Gay was the honorary chair. This theme offered the public the opportunity to explore oral histories both as acts of preservation and as artifacts that require preservation. Libraries, institutions, and museums held virtual events April 26-May 2, and ALCTS hosted the free Preservation Week webinars "Using Oral History to Tell Your Family Stories" and "Community Archiving Strategies for Oral History" during the week. Preservation Week is a collaborative effort supported by ALCTS, the Library of Congress, and the Institute of Museum and Library Services.

\section{ALCTS Publications}

From September 1 to June 8, 2020, ALCTS News published nine feature articles, six columns, and ten announcements (some articles are categorized as more than one item.) Chelcie Rowell continued to post conference reports to ALAIR. The monthly electronic newsletter ALCTS Connect moved from monthly to being sent every other month. The January/February ALCTS Connect was sent in early February and the March/April ALCTS Connect was sent in early April. The average open rate was 30 percent.

From January 1 to May 31, 2020, thirteen papers were submitted for publication in Library Resources and Technical Services (LRTS) journal, an increase from the eight papers submitted for the period of January 1 to June 1 , 2019. Two papers were published, three rejected, and the others are in various stages of review. A total of thirty-two papers were submitted during 2019. Because of the pandemic, the search committee for the LRTS Editor position decided to suspend the search and extend terms for the journal's current editors for an additional year. Current LRTS Editor Mary Beth Weber and current LRTS Book Review Editor Elyssa Gould will continue in those roles through December 2021. As of April 2020, LRTS has 137 subscribers.

Three ALCTS monographs were published in 2020Linked Data for the Perplexed Librarian, The Library's Guide to Graphic Novels, and The Library Liaison's Training Guide to Collection Management. The second guide in the ALCTS Monographs Sudden Position Series, the Sudden Position Guide to Collection Management, and the Sudden Selector's Guide series guides Sudden Selector's Guide to Geography and GIS and Sudden Selector's Guide to Romance Languages and Literatures, were also published in 2020. Comprising members from both academic and public libraries and one member from the Library of Congress, the ALCTS Monographs Editorial Board provides ALCTS members an opportunity to serve as board members and provides an opportunity for ALCTS members to publish. The Board is currently developing a proposal for a monograph covering diversity and inclusiveness.

ALCTS Publications Committee members will be reaching out to Exchange virtual conference presenters about writing for ALCTS. Members of the committee are looking forward to offering their expertise in working with ALCTS publications to contribute to designing a plan for publications within the new division and its new sections.

\section{ALCTS Leadership Development/ Mentoring Program}

The ALCTS Mentoring Subcommittee spent the year supporting the program's third cohort of twenty-eight mentor/ mentee pairs, which ended on April 30, 2020. The subcommittee also reviewed applications for the fourth cohort and matched mentors with mentees for a total of thirty-one pairs whose mentorships began in June 2020. In collaboration with the LLAMA Mentoring Committee, participation in this year's mentoring program was opened to current members of ALCTS, LLAMA, and LITA, and applications were received from members across all three divisions. The ALCTS Leadership Development Committee continued the development of a LibGuide as a resource for ALCTS leaders and delivered a webinar on virtual meeting best practices for ALCTS leaders to support the ALCTS strategic goal to increase virtual participation in events. 


\section{ALCTS Standards Development Activities}

With the approval of Core, the ALCTS Standards Committee proactively began brainstorming a new charge to incorporate the new division's mission plus other standards committees, and identified the CRS Standards Committee as one such committee with which to merge. Prior to the 2019 ALA Annual Conference and 2020 Midwinter Meeting, the committee distributed a list of standards-related ALCTS programming to a variety of discussion lists that will also be posted on its LibGuide.

The Metadata Standards Committee held monthly online meetings to continue working on the Assessing Metadata Framework. The Framework is a rubric used to determine the quality of a metadata standard for a given project. The committee wrote an executive summary to accompany the Framework, and sought feedback from the community during ALA Midwinter.

Joelen Pastva began her role as the new ALA representative to National Information Standards Organization (NISO). Other ALCTS Committees within the Cataloging and Metadata Management Section (CaMMS) continued their work to discuss and provide input into metadata-related standards. The Committee on Cataloging: Description and Access (CC:DA) contributed to the revision of $R D A$ : Resource Description and Access. Stephen Hearn and Dominique Bourassa, ALA's two representatives to NARDAC (North American RDA Advisory Committee) continued to collaborate with CC:DA to obtain input into revisions to the RDA Toolkit as part of the 3R Project, which is in its final stages. The Subject Analysis Committee (SAC) studied and made recommendations related to a variety of subject and genre/form vocabularies used to organize information, including discussing possible alternatives to the use of the Library of Congress Subject Heading "Illegal aliens". Since the Midwinter Meeting, SAC's Subcommittee on Faceted Vocabularies completed their "Best Practices for Faceted Chronological Data" and the "Illegal aliens" working group completed their report and started developing a website to house accompanying documents.

\section{Advocacy}

The ALCTS Advocacy and Policy Committee received reports from liaisons to ALA's Committee on Library Advocacy (COLA) and the ALA Committee on Legislation. The chair took ALA Bystander Training in September and shared notes from that class. The committee discussed updates on Core and possible future work, such as developing statements of value for generic technical services positions. Committee members also recommended that CORE have a seat on the ALA Advocacy Committee, and identified the need for a group that advocates specifically for technical services staff within ALA and libraries.

\section{Organizational Changes}

\section{Transitioning from ALCTS to Core}

During this transitional year, much of the focus of ALCTS leaders and staff was on planning for the possible creation of a new division with LITA and LLAMA. Throughout Fall 2019, a revised Steering Committee and new project teams agreed on the new name for the proposed division and worked through all operational aspects of the new division. A Communications Working Group developed and implemented an intense member communication campaign, including in-person and virtual town halls, focus groups, surveys, and countless updates through email, social media, and a new website. In December, the final project plan was shared with members, including the proposed bylaws. Throughout the spring, communication continued, and each division held a final set of virtual town halls. In the spring election, ninety-one percent of ALCTS members who voted supported the creation of Core, and the other division members also overwhelmingly voted to support Core-with ninety-six percent yes for both divisions.

In May, new working groups were launched to lead the transition, with the remainder of the summer devoted to winding down ALCTS and planning for Core. The final reports of these groups were submitted in early August. A virtual celebration attended by members of ALCTS, LITA, and LLAMA took place at the conclusion of the Virtual ALA Annual.

\section{ALCTS Finances}

A variety of factors converged during the early months of 2020 to complicate ALCTS's financial situation. The overall ALA budget situation worsened in FY20. At the ALA Midwinter Meeting in Philadelphia, ALA announced that much of its cash and short-term reserves, including those reserves built up by the divisions, had been used to cover operating deficits, and that cash flow to pay bills remained a concern. ALA applied for and received some relief under the Payroll Protection Program, but with even lower revenue due to COVID-19, the deficit increased, and staff were informed that they would be required to take one week of furlough in August 2020 and five weeks of furlough throughout FY21.

ALA's budget situation worsened considerably again due to COVID-19 and the resulting cancellation of the inperson ALA Annual Conference. This situation prompted ALCTS to co-sign a letter with ALA member divisions the 
Association of College \& Research Libraries (ACRL), the Association for Library Service to Children (ALSC), the Public Library Association (PLA), LITA, LLAMA, and the Reference \& User Services Association (RUSA) that was sent to the ALA Executive Board requesting more information about how ALA planned to address this situation and expressing concern for the well-being of ALA staff given the planned furloughs. With a signification portion of the ALA accounting function transferred to an overseas firm, ALCTS staff were unable to access financial reports for up to six months due to COVID-19, making it impossible to report on the state of ALCTS finances as ALCTS wound down its activities. Once the results of the member votes to create Core were announced in April, ALCTS leaders and staff focused on planning for the financial sustainability of the new division within the context of ALCTS's relatively strong financial situation prior to ALA's overall financial difficulties.

\section{ALA and COVID-19}

ALA staff began to work from home in March 2020 as a result of the COVID-19 pandemic. Even while working remotely, staff continued to provide webinars, repurposed Annual Conference programming for virtual presentations in the fall, and planned for the Core launch on September 1.

ALA's move to a new office in April was delayed until June due to COVID-19. In May, ALCTS staff packed the old office area, and most of the move was completed by early June. ALA had scheduled the official return to the office date for September 8, however, after reassessing the return plans, and evaluating the handling of the pandemic in the Chicago area, ALA decided that staff would remain working remotely through 2020. Although Core staff was unable to start as a new division on-site in the new ALA headquarters, they have been diligently working together and with members of the new division, and have begun the tasks of building this new organization within ALA.

\section{Moving Forward}

As ALCTS Past President, I would like to express my appreciation to my colleagues on the ALCTS Executive Committee (Kristin Martin, ALCTS Past President; Chris Cronin, Incoming ALCTS President; Erin Stalberg, ALCTS Councilor; Kerry Ward, ALCTS Interim Executive Director; and Julie Reese, ALCTS Deputy Director) and to the entire ALCTS Board for their support this past year, their service to ALCTS, and their visionary leadership in supporting the transition from ALCTS to Core. Thank you as well to all ALCTS members who participated in the organization's work this year or helped to shape the future of our work in our new division. Thank you also to everyone (including the several past ALCTS Presidents) who attended the ALCTS Virtual Happy Hour in July for creating such a joyous event where we could reminisce about ALCTS while still looking forward to the future with excitement. While our future as an organization still looks uncertain in some ways, we are well positioned to make the changes that will be required in the coming years to support our profession. 